\title{
Calcium is a key factor in $\alpha$-synuclein induced neurotoxicity
}

Plamena R. Angelova ${ }^{\wedge}$, Marthe H.R. Ludtmann ${ }^{\wedge 1}$, Mathew H. Horrocks ${ }^{2}$, Alexander Negoda ${ }^{3}$, Nunilo Cremades $^{2}$, David Klenerman ${ }^{2}$, Christopher M. Dobson², Nicholas W. Wood ${ }^{1}$, Evgeny V. Pavlov, Sonia Gandhi ${ }^{* 1}$, Andrey Y. Abramov ${ }^{* 1}$

${ }^{1}$ UCL Institute of Neurology, Queen Square, London WCIN 3BG, UK; ${ }^{2}$ Department of Chemistry, University of Cambridge, Cambridge, UK; ${ }^{3}$ Department of Physiology and Biophysics, Dalhousie University, Halifax, Canada;; ${ }^{4}$ College of Dentistry, New York University, New York, USA

* Joint senior authors

To whom correspondence should be addressed: Andrey Y. Abramov or Sonia Gandhi, UCL Institute of Neurology, Queen Square House, Queen Square, London, UK, WC1N 3BG,

Tel.: (+44) 203448 4062; E-mail: a.abramov@ucl.ac.uk, sonia.gandhi@ucl.ac.uk 


\begin{abstract}
Aggregation of $\alpha$-synuclein leads to the formation of oligomeric intermediates that can interact with membranes to form pores. However it is unknown how this leads to cell toxicity in Parkinson's disease. We investigated the species-specific effects of $\alpha$ synuclein on calcium signalling in primary neurons and astrocytes using live neuronal imaging and electrophysiology on artificial membranes. We demonstrate that $\alpha$ synuclein induces an increase in basal intracellular calcium in its unfolded monomeric state as well as in its oligomeric state. Electrophysiology of artificial membranes demonstrated that $\alpha$-synuclein monomers induce irregular ionic currents, while $\alpha$ synuclein oligomers induce rare discrete channel formation. Despite the ability for monomeric $\alpha$-synuclein to affect calcium signalling, it is only the oligomeric form of $\alpha$ synuclein that induces cell death. Oligomer-induced cell death was abolished by the exclusion of extracellular calcium, which prevented the $\alpha$-synuclein induced calcium dysregulation. The findings of this study confirm that $\alpha$-synuclein interacts with membranes to affect calcium signalling in a structure-specific manner and the oligomeric beta sheet rich $\alpha$-synuclein species ultimately leads to calcium dysregulation and calcium dependent cell death.
\end{abstract}

Keywords: $\alpha$-synuclein, calcium signalling, Parkinson's disease, neuronal death 


\section{Introduction}

Neurodegenerative diseases share a common pathological process of misfolding of a native monomeric protein into a range of intermediate oligomeric structures, and finally polymerising into insoluble amyloid fibrils and depositing in the brain as inclusions. In Parkinson's disease (PD) it is the native protein $\alpha$-synuclein that undergoes self-aggregation, and deposition in Lewy bodies (Cookson, 2009). Extensive evidence now suggests that the smaller and soluble intermediate products of $\alpha$-synuclein aggregation (termed oligomers) are likely to be the pathogenic culprits of disease (Kalia et al., 2013). During the aggregation process, monomeric $\alpha$-synuclein initially forms oligomers (2 mer-50 mers) that are unstructured, degradable and non-toxic to cells. These then undergo a conversion to highly compact and beta sheet structured oligomers that are stable and toxic to cells (Cremades et al., 2012). Complementary in vivo studies have demonstrated that overexpression of oligomer forming variants of $\alpha$-synuclein in rat substantia nigra induces significant dopaminergic neuronal death, whereas overexpression of fibril forming variants of $\alpha$-synuclein does not demonstrate significant toxicity (Winner et al., 2011). Intermediate species of aggregated $\alpha-$ synuclein may also be transferred between neurons and induce toxicity as well as seed further aggregation in recipient neurons in vitro (Desplats et al., 2009) and in vivo (Hansen et al., 2011; Volpicelli-Daley et al., 2011). However the nature and mode of action of the structural forms of these toxic intermediate aggregates remains unclear.

Calcium dysregulation has been reported previously in alpha-synucleinopathy models of PD, and there are a number of ways in which $\alpha$-synuclein and calcium may be linked. Overexpression of intracellular $\alpha$-synuclein in neuroblastoma cell models has been associated with alterations in basal and depolarising stimulus evoked calcium signals (Danzer et al., 2007). $\alpha$-synuclein itself, in its annular oligomeric form, can induce a calcium flux across 
artificial membranes and neuronal membranes through pore forming mechanisms (Danzer et al., 2007). High levels of intracellular calcium induced either by thapsigargin, ionophores, or depolarising stimuli can promote the intracellular oligomerisation and aggregation of $\alpha$ synuclein. The removal of calcium in these experiments is able to prevent $\alpha$-synuclein aggregation. Thus there is a complex loop in which $\alpha$-synuclein expression and abnormal aggregation may initially promote calcium dysregulation, which may in turn promote further aggregation (Follett et al., 2013; Nath et al., 2011).

Although it has been reported that oligomers of aggregated proteins may induce calcium fluxes across membranes in vitro, the exact structural species of the protein responsible, the source of the calcium signal in cells, the impact on physiological calcium signalling, and the role in neuronal death, and have not been elucidated. In this study we have utilised a range of biophysical methods, live neuronal imaging, and electrophysiology to dissect which conformational variant of $\alpha$-synuclein induces a calcium signal in neurons, the mechanism of $\alpha$-synuclein induced calcium dysregulation and the consequence of calcium dysregulation on cell toxicity. 


\section{Results}

\section{Monomeric and oligomeric a-synuclein both induce $\left[\mathrm{Ca}^{2+}\right]_{c}$ rise in neurons and astrocytes.}

We wished to determine whether $\alpha$-synuclein itself was able to induce a calcium signal, and which conformational state determined this signal. We therefore generated monomeric and oligomeric species of $\alpha$-synuclein and tested their effect on primary neurons and astrocytes, iPSC derived human neurons, and acute brain slices. We utilised two different methods for the preparation of different $\alpha$-synuclein species. In Method 1, we add Alexa Fluor (AF) 594 (or AF647) labelled monomeric $\alpha$-synuclein to AF 488 labelled monomeric $\alpha$-synuclein in a 1:1 ratio. As the aggregation proceeds, oligomers consisting of both the AF488- $\alpha$-synuclein and the AF594- $\alpha$-synuclein will form, and, as the AF488- $\alpha$-synuclein acts as a FRET donor, and the AF594- $\alpha$-synuclein a FRET acceptor, we can use single-molecule confocal FRET analysis to differentiate the oligomeric $\alpha$-synuclein from the rest of the monomeric protein. Moreover we can further utilize the FRET efficiency analysis to determine the formation of the compact, beta-sheet containing oligomers (Cremades et al., 2012). Following aggregation for 29 hours, we detect $~ 0.8 \%$ oligomers (number of detected oligomers as a fraction of total number of detected events). These consist of two populations of oligomers: $82 \%$ formed a high FRET efficiency population $(E=0.62$;Figure $1 \mathrm{~A})$ characteristic of the compact, beta sheet oligomers previously identified (Cremades et al., 2012), and 18\% had formed a low FRET efficiency oligomer population $(\mathrm{E}=0.41$, Figure 1A).

As this method generates a mixture of monomers and oligomers, we also utilised a second method based on lyophilisation (Method 2) to generate an enriched oligomer preparation, which allowed us to determine oligomer specific effects on cells. The enriched oligomers generated in this method have been extensively characterised and reported in (Chen et al., 
2015). Using this method, we were able to generate a preparation containing $>90 \%$ oligomers. These oligomers are of cylindrical structures, composed of 10-40 protein molecules and a beta sheet content of 30-40\%.

It is well established that $\alpha$-synuclein is present extracellularly, and we, and others, have shown that it is rapidly taken up by neurons and astrocytes in is monomeric, oligomeric and fibrillar forms (Cremades et al., 2012). Application of monomeric and oligomeric $\alpha$-synuclein induces a cytosolic calcium signal in both neurons and astrocytes. In these experiments cells loaded with the calcium indicator were initially observed at basal levels for 2 minutes prior to application of $\alpha$-synuclein. Cells that exhibited spontaneous oscillations prior to addition of $\alpha$-synuclein were excluded from the analysis. The $\alpha$-synuclein species was then added to the cells and recordings are taken for 30-40minutes. Two patterns of $\alpha$-synuclein induced calcium signal were observed. Oligomeric $\alpha$-synuclein induces a transient calcium signal, consisting of calcium spikes, with and without complete recovery to baseline, at a concentration range of 40-250nM, after 2-6 minutes (Figure 1D; $\mathrm{n}=189$ ). Monomeric $\alpha$ synuclein induces transient calcium spikes superimposed on a gradual increase in the basal calcium signal (Figure 1C; $n=568$ ). We report that the amplitude and shape of the $\alpha$-synuclein induced calcium signal was consistently one of these patterns, and appeared to be independent of the concentration of $\alpha$-synuclein applied. Fig 1E demonstrates the number of cells exhibiting a calcium response in a dose response experiment performed on cells of the same batch at the same DIV, using the same preparation of aggregated $\alpha$-synuclein. At concentrations of $100 \mathrm{nM}$ (oligomer $1 \mathrm{nM}$ ), $11.5 \pm 6.3 \%$ cells responded; at $250 \mathrm{nM}$ (oligomer $2.5 \mathrm{nM}$ ), $13.0 \pm 4.1 \%$ cells responded; at $500 \mathrm{nM}$ (oligomer $5 \mathrm{nM}$ ), $26.8 \pm 17.6 \%$ cells responded; at $750 \mathrm{nM}$ (oligomer $7.5 \mathrm{nM}$ ), $25.7 \pm 21.9 \%$ cells responded; at $1.75 \mu \mathrm{M}$ (oligomer $17.5 \mathrm{nM}$ ); $75.6 \pm 5.6 \%$ cells responded. In summary, the amplitude of the $\alpha$-synuclein induced calcium signal did not vary with dose. However the number of cells in the culture that responded to 
extracellular $\alpha$-synuclein did vary, increasing with higher concentrations of $\alpha$-synuclein. Fig 1F demonstrates the quantification of the observed patterns of calcium signalling induced by $\alpha$-synuclein in the representative dose response experiment shown in fig $1 \mathrm{E}$. Monomers alone induced a sustained rise in basal calcium $(23.1 \pm 3.5 \%, \mathrm{n}=32)$, or transient spikes $(7.1 \pm 2.5 \%$, $\mathrm{n}=7)$, or a mixed pattern $(69.8 \pm 10.2 \%, \mathrm{n}=59)$. Oligomers induced a sustained rise in basal calcium $(4.6 \pm 3.8 \%, \mathrm{n}=3)$, or transient spikes $(6.0 \pm 4.2 \%, \mathrm{n}=11)$ or a mixed pattern $(92.4 \pm 3.5 \%, \mathrm{n}=169)$. Thus overall, we show that the majority of cells will exhibit both transient calcium spikes as well as a sustained rise in basal calcium. A small proportion of cells will demonstrate exclusively a sustained rise in basal calcium particularly on exposure to monomers.

The physiological concentrations of extracellular $\alpha$-synuclein are estimated to be in the low nanomolar range for monomer (based on the estimated concentration of extracellular alphasynuclein in CSF studies), and, as only $1 \%$ of the monomeric form aggregates, it is estimated to be in the picomolar range for oligomers. We were able to detect $\alpha$-synuclein induced calcium signals as low as 10nM (for monomer) and 100pM (for oligomer). However at these concentrations $<5 \%$ of the cells in the culture responded. Therefore for all further experiments, concentrations of $\alpha$-synuclein were employed that ensured a calcium signal in at least $30 \%$ cells. Of note, the $\alpha$-synuclein-induced calcium signal was independent of cell type and was observed in both neurons and astrocytes, and independent of brain region as it was observed in primary co-cultures from midbrain and cortex, but also from human cortical neurons derived from iPSCs (Figure 1G). Furthermore the oligomer induced calcium signal was also observed in ex vivo brain slices from rat cortex loaded with fura-2 (Figure 1B, n=59 cells from 5 slices).

As both the monomeric and oligomeric $\alpha$-synuclein induced a calcium signal in neurons, we also applied the enriched oligomer preparation (from method 2) to primary co-cultures to 
determine whether oligomeric $\alpha$-synuclein alone induced a calcium signal. We observed a similar $\alpha$-synuclein calcium signal ( $\mathrm{n}=5$ experiments; Figure $1 \mathrm{H})$ to that observed with the oligomeric $\alpha$-synuclein generated by method 1 .

\section{The a-synuclein induced calcium signal is dependent on influx of extracellular calcium}

Next we investigated the source of the $\alpha$-synuclein induced calcium signal in primary cocultures. We applied monomeric and oligomeric $\alpha$-synuclein to wild type primary cells in calcium free medium $\left(\mathrm{Ca}^{2+}\right.$-free $\mathrm{HBSS}+0.5 \mathrm{mM}$ EGTA $\left.+1.25 \mathrm{mM} \mathrm{Mg} \mathrm{Cl}_{2}\right)$ and demonstrated that $\alpha$-synuclein no longer induced any calcium signal (Figure 2A-B), suggesting that external calcium is crucial for the $\alpha$-synuclein induced calcium signal.

The transient and oscillatory $\left[\mathrm{Ca}^{2+}\right]_{\mathrm{c}}$ signals mirror those seen in ER $\left[\mathrm{Ca}^{2+}\right]_{\mathrm{c}}$ release induced by IP3. External $\mathrm{Ca}^{2+}$ can activate phospholipase $\mathrm{C}$ (PLC), which could in turn generate IP3 and thus mobilise ER $\mathrm{Ca}^{2+}$. To assess this hypothesis, we employed U73122 $(5 \mu \mathrm{M})$, an inhibitor of phospholipase $\mathrm{C}$ (Figure 2C) which did not significantly alter the monomeric or oligomeric $\alpha$-synuclein induced $\left[\mathrm{Ca}^{2+}\right]_{\mathrm{c}}$ astrocyte and neuronal signals ( $\mathrm{n}=98$ cells). Similarly, Xestospongin $\mathrm{C}(10 \mu \mathrm{M})$, an inhibitor of $\mathrm{IP}_{3}$-dependent $\mathrm{Ca}^{2+}$ release, failed to reduce the oligomeric- $\alpha$-synuclein -induced $\left[\mathrm{Ca}^{2+}\right]_{\mathrm{c}}$ signals in astrocytes and neurons $(\mathrm{n}=123$ cells; Figure 2C). Both U73122 and Xestospongin C completely blocked ATP-induced calcium signal in astrocytes at this concentrations (Domijan et al., 2014). Therefore, these data confirm that the PLC- and IP3- mediated calcium signalling does not contribute significantly to the $\alpha$-synuclein induced $\left[\mathrm{Ca}^{2+}\right]_{\mathrm{c}}$ responses.

We applied $0.5-\mu \mathrm{M}$ thapsigargin (an inhibitor of $\mathrm{ER} \mathrm{Ca}^{2+}$ pumps) to primary co-cultures in order to deplete $\mathrm{Ca}^{2+}$ from the ER. To ensure that the concentration of thapsigargin was adequate for complete ER depletion of calcium, ATP was then applied to the culture, and this did not induce a cytosolic calcium response. This was followed by the addition of monomeric 
(Figure 2D; n=199) or oligomeric (Figure 2E; n=218) $\alpha$-synuclein which still induced a similar $\left[\mathrm{Ca}^{2+}\right]_{\mathrm{c}}$ response as before. Taken together, these data strongly suggest that ER $\mathrm{Ca}^{2+}$ does not contribute to the $\alpha$-synuclein induced $\left[\mathrm{Ca}^{2+}\right]_{\mathrm{c}}$ responses.

Having excluded intracellular calcium stores as the source of the $\alpha$-synuclein induced calcium signal, we assessed whether $\alpha$-synuclein species induced calcium influx into cells from the extracellular media. We employed the manganese $\left(\mathrm{Mn}^{2+}\right)$-induced quenching technique: fura-indicators irreversibly bind $\mathrm{Mn}^{2+}$ and this quenches their fluorescence. The $\mathrm{Mn}^{2+}$ quench process can be quantified by measuring the fluorescence of fura- 2 at its isobestic wavelength at $\sim 360 \mathrm{~nm}$. $\mathrm{Mn}^{2+}$, when applied extracellularly, will enter cells via $\mathrm{Ca}^{2+}$ permeable channels, and thus the $\mathrm{Mn}^{2+}$ entry via calcium channels can be quantified using the emission of fura-2 at $360 \mathrm{nM}$ (while the $\mathrm{Ca}^{2+}$ dependent changes of the $340 / 380 \mathrm{~nm}$ ratio of fura- 2 are not altered). As a control, in the presence of monomeric (Figure 3C; $n=62$ cells) $\alpha$ synuclein but in the absence of $\mathrm{Mn}^{2+}$, the Fura-2 signal excited at $360 \mathrm{~nm}$ was unaltered showing that this method reliably reports a $\mathrm{Ca}^{2+}$ independent signal (Figure 3C, left $\mathrm{Y}$-axis, black). However, in the presence of $40 \mu \mathrm{M} \mathrm{Mn}^{2+}$ and monomeric $\alpha$-synuclein (Figure 3A) or oligomeric alpha-synuclein (Figure 3B; $n=81$ cells), the Fura-2 signal at 360nm showed steplike irreversible decreases (quench) confirming the entry of $\mathrm{Mn}^{2+}$ via $\mathrm{Ca}^{2+}$ permeant channels. Each quench directly corresponds to the $\alpha$-synuclein-induced transient increase in $\left[\mathrm{Ca}^{2+}\right]_{\mathrm{c}}$ (example traces are shown in Figure 3A-B, right $\mathrm{Y}$-axis, red). These results suggest that the $\alpha$-synuclein induced transient $\left[\mathrm{Ca}^{2+}\right]_{\mathrm{c}}$ signals are caused by pulses of $\mathrm{Ca}^{2+}$ influx from the extracellular media into astrocytes and neurons across the plasmalemmal membrane via $\mathrm{Ca}^{2+}$ permeant channels .

We then investigated whether the $\alpha$-synuclein calcium influx across the plasmalemmal membrane occurred via the known voltage dependent calcium channels or glutamate receptor mechanisms. We first incubated primary cultures with a variety of inhibitors of channels and 
receptors for 10 minutes, and then applied $\alpha$-synuclein in order to determine their effect on the calcium signal induced by monomers and oligomers. The concentration of these inhibitors has been previously tested and confirmed to induce inhibition of their channels or receptors. Nifedipine $(1 \mu \mathrm{M})$ or Verapamil $(20 \mu \mathrm{M})$, inhibitors of L-type VDCCs, did not alter the shape or amplitude of the monomeric (data not shown) or oligomeric (Figure 3C) $\alpha$-synuclein induced $\left[\mathrm{Ca}^{2+}\right]_{\mathrm{c}}$ signals in either astrocytes $(\mathrm{n}=58$ for monomers, $\mathrm{n}=48$ for oligomers) or neurons ( $\mathrm{n}=39, \mathrm{n}=62$ for both types of $\alpha$-synuclein). Inhibitors of either ionotropic or metabotropic glutamate receptors, including $20 \mu \mathrm{M}$ CNQX ( $\mathrm{n}=156$ cells), $10 \mu \mathrm{M}$ MK-801 ( $\mathrm{n}=286$ cells) or $50 \mu \mathrm{M}(\mathrm{S})$-MCPG ( $\mathrm{n}=215$ cells), did not have any effect on the $\alpha$-synuclein induced calcium signals, as shown on Figure 3C. These results suggest that the monomeric and oligomeric induced calcium signal are not reflective of glutamate release in the culture, and are not dependent on known voltage dependent calcium channels.

\section{Effect of monomeric $\alpha$-synuclein on $\mathrm{Ca}^{2+}$ efflux}

In addition to the $\alpha$-synuclein induced calcium signal caused by calcium influx, we investigated whether the presence of $\alpha$-synuclein was able to affect calcium responses to physiological stimuli, such as depolarising stimuli: glutamate and $\mathrm{KCl}$ in neurons, and nondepolarising stimuli such as ATP in astrocytes. We therefore pre-incubated astrocytes and neurons with monomeric $\alpha$-synuclein for 10 minutes. Subsequent stimulation of neurons with $5 \mu \mathrm{M}$ glutamate resulted in a significantly slower $\left[\mathrm{Ca}^{2+}\right]_{\mathrm{c}}$ efflux in neurons when compared to control $(0.936 \pm 0.021 \mathrm{~min}, \mathrm{n}=91$ vs. $2.639 \pm 0.208 \mathrm{~min}, \mathrm{n}=68, \mathrm{p}<0.05$; Figure $4 A-B)$.

These results suggest that monomeric $\alpha$-synuclein not only induces $\mathrm{Ca}^{2+}$ influx into cells but also significantly inhibits $\mathrm{Ca}^{2+}$ efflux. This inhibition of the $\mathrm{Ca}^{2+}$ efflux causes the slow decay of the calcium signal induced by stimuli and further may contribute to the slow and progressive basal $\left[\mathrm{Ca}^{2+}\right]_{\mathrm{c}}$ increase in neurons and astrocytes exposed to $\alpha$-synuclein. 


\section{Effect of a-synuclein on conductance of artificial lipid membranes}

We sought to determine the ability of $\alpha$-synuclein to directly induce ionic permeability of lipid membranes and so we performed a series of experiments using phospholipid bilayer membranes and synthetic monomeric and oligomeric $\alpha$-synuclein generated by aggregating fluorescently labelled $\alpha$-synuclein (method 1). In our experiments we used the planar lipid bilayer (BLM) approach. This approach allows use of artificial membranes formed by pure lipids without participation of protein components, which are normally present in biological membranes. We detected that addition of oligomeric $\alpha$-synuclein to the recording causes an increase in membrane permeability. We observed two distinct conductance modes consistent with channel like behaviour of this protein. The first mode is characterized by stable open state with no transitions to closed or sub-conductance states (Figure 5A, conductance $=92.7$ $\pm 2.3 \mathrm{pS}$ ). This type of conductance was observed in 3 independent experiments. The second mode is characterized by stable channel activity with distinct transitions between open and closed states (Figure 5B, conductance $24.2 \pm 2.7 \mathrm{pS}$ ). It should be noted that channel activity was a relatively rare event which was detected in only $\sim 20 \%$ of the experiments $(n=30)$. Both of these channel modes were cation selective. In the presence of 10:1 $\mathrm{NaCl}$ concentration gradient across the lipid membrane the reversal potential (zero current potential) was $57 \mathrm{mV}$, which is close to the theoretical Nernst potential for sodium ion selectivity under these conditions $(58 \mathrm{mV})$ (Figure $5 \mathrm{C}$ ). These channels, however, were not selective between sodium and calcium. Importantly, channel activity was detected only in the presence of oligomeric but not monomeric $\alpha$-synuclein species. We should note that in addition to the channel activity we detected irregular ionic currents in the bilayer (Figure 5D). This activity was observed in the presence of monomeric as well as in the presence of oligomeric samples. This suggests that irregular conductance in the presence of oligomeric sample was likely due to the presence of monomeric $\alpha$-synuclein in the sample. These data show that both 
monomeric and oligomeric $\alpha$-synucleins are capable of increasing the permeability of lipid membranes. However, only oligomeric forms can form ion channels with stable conductance.

Overall these data suggest that oligomers might disrupt lipid membranes through different mechanisms that may depend on the lipid composition, the curvature of the lipid bilayer and the protein:lipid ratio.

\section{Calcium signalling and toxicity}

Since calcium dysregulation is known to be a key player in cell death induction we investigated whether the $\alpha$-synuclein-induced calcium signal leads to neurotoxicity and ultimately cell death. We treated primary co-cultures with monomeric or oligomeric $\alpha$ synuclein, assessed caspase- 3 activation using the fluorescent labelled caspase- 3 substrate NucView and recorded the number of cells undergoing apoptosis over 30 min period. We found that within 15 minutes, a significant percentage of cells exposed to oligomeric, but not monomeric $\alpha$-synuclein, started to undergo apoptosis (representative images shown in Figure 6A, representative traces of cells loaded with NucView shown in Figure 6C). We then applied the same monomeric and oligomeric $\alpha$-synuclein preparations to cells in calcium-free HBSS. The percentage of cells undergoing apoptosis induced by oligomeric $\alpha$-synuclein was reduced significantly (from 27.9 $\pm 7.2, \mathrm{n}=32$ to $11.5 \pm 0.5, \mathrm{n}=37, \mathrm{p}=0.0012$; Figure $6 \mathrm{~B}$ ). In order to assess prolonged exposure to $\alpha$-synuclein, we incubated the cells in normal and calciumfree DMEM, containing monomeric or oligomeric $\alpha$-synuclein for 6 hours, and counted the number of Hoechst/PI positive cells (representative images shown in Figure 6D). We showed that oligomeric $\alpha$-synuclein, but not monomeric $\alpha$-synuclein, induced significant cell death after 6 hours, which was prevented by exclusion of calcium from the extracellular medium (from $49.0 \% \pm 4.1, \mathrm{n}=32$ to $14.3 \% \pm 1.1, \mathrm{n}=37, \mathrm{p}=0.0302$; Figure $6 \mathrm{E}$ ). 


\section{Discussion}

In this study we sought to unravel the link between misfolded $\alpha$-synuclein protein and aberrant calcium signals and dyshomeostasis and neuronal death in Parkinson's disease. Extracellular $\alpha$-synuclein is taken up by cells rapidly and is responsible for subsequent transmission of pathology, both in terms of inducing neuronal death as well as seeding further aggregation. However the initial pathophysiological effect of extracellular $\alpha$-synuclein on a cell is not well delineated, and the species specific form of extracellular $\alpha$-synuclein and its correlative cellular effects are also poorly established. Our model of applying different conformational species of $\alpha$-synuclein to cells and observing the immediate effects on calcium signalling is therefore highly relevant to understand the species specific effects of $\alpha$ synuclein. We utilised recombinant $\alpha$-synuclein at different stages of aggregation and applied these preparations to neurons and astrocytes. Detailed biophysical characterisation of two different preparations of oligomers confirm that we have generated oligomers that are stable, resistant to proteinase K degradation, and rich in beta sheet structure. Such oligomers are formed late in the aggregation process and are proposed to be the more toxic to cells due to their ability to interact with membranes. We showed that exogenously applied monomers and oligomers are in fact both able to induce cytosolic calcium signal at nanomolar concentrations in a range of models: primary neurons, iPSC-derived neurons and acute brain slices. Extracellular $\alpha$-synuclein was able to induce two different patterns of cytosolic calcium signalling: (1) a gradual increase in the basal cytosolic calcium level and (2) transient calcium spikes. Patterns (1) and (2) could occur distinctly or in combination in the same cell. However the monomer and oligomer induced calcium signal was entirely dependent on the presence of extracellular calcium. Thus, both monomeric and oligomeric $\alpha$-synuclein induce a cytosolic calcium signal in cells by inducing pulses of calcium influx across the plasmalemmal membrane through calcium permeable channels. 
It is well established that $\alpha$-synuclein binds negatively charged phospholipids, and thus binds to membranes. Monomeric $\alpha$-synuclein assumes $\alpha$-helical structure on binding which is thermodynamically favourable, while the oligomeric (or protofibrillar form) binds membranes with higher affinity than monomers and retains a beta sheet structure. There are currently two major biophysical hypotheses that explain the calcium influx seen with aggregated $\alpha$-synuclein: (1) the amyloid pore hypothesis in which oligomeric $\alpha$-synuclein is able to form pore-like structures with non-selective leakage of compounds (Volles et al., 2001). AFM, CD, and electrophysiology have demonstrated the formation of ion channels by soluble amyloid subunits in membrane bilayers that display multilevel conductances reflective of the number of units forming the channel (Quist et al., 2005). The alternative hypothesis is (2) the incorporation of oligomeric species in between tightly packed lipids in the bilayer membrane results in reduced lipid order, thinning of the membrane and reduction in the dielectric barrier and an increase in membrane permeability (and hence conductance) in the absence of ion channel formation (Kayed et al., 2004; Sokolov et al., 2006).

Monomers of $\alpha$-synuclein have also been reported to affect membranes through differing mechanisms, that is, altering permeability or inducing channel formation. High concentrations of monomers have been shown to permeabilise membranes through detergent like mechanisms (Volles and Lansbury, Jr., 2002). One study demonstrated that monomeric $\alpha$-synuclein formed discrete highly conductive ion channels in planar BLM in the presence of a transmembrane potential. Importantly these channels were voltage sensing as the structural changes in $\alpha$-synuclein were dependent on the membrane potential, favouring insertion into depolarised membranes (Zakharov et al., 2007).

In order to understand the effect of our monomeric and oligomeric species of $\alpha$-synuclein on membranes, we applied them to artificial bilayer membranes and recorded changes in conductance. In agreement with the monomeric and oligomeric $\alpha$-synuclein induced calcium 
signal in cells, our bilayer membrane data suggest that the presence of both monomeric and oligomeric $\alpha$-synuclein causes an increase in lipid membrane permeability. In the presence of monomeric $\alpha$-synuclein, membrane conductance was highly irregular with frequent "spikes" of ionic currents. Conversely, in the presence of oligomeric $\alpha$-synuclein, we detected ion currents with distinct stable conductance levels, which are typical for ion channels and pores. For both monomers and oligomers, their effect on cell membrane conductance and calcium influx can therefore be explained by their direct interaction between cell lipid membranes and the protein. Overall our data is in agreement with both hypotheses of the interaction of monomers and oligomers with membranes: lipid thinning and resultant increase in permeability leads to ionic currents and calcium spiking with both monomers and oligomers. However in the case of oligomers, membrane permeabilization produces a stronger effect likely due to the formation of stable pores resulting in rare but regularly occurring ion channel formation. Thus the $\alpha$-synuclein induced calcium signal seen in cells is due to the interaction of monomeric and oligomeric $\alpha$-synuclein with the neuronal membrane affecting its permeability and allowing different types of calcium influx to occur.

Finally we wished to understand the relationship between the aberrant calcium signals, impaired calcium homeostasis and cell death in Parkinson's disease. We report that although monomeric and oligomeric forms of $\alpha$-synuclein both induce calcium signals, it is only the oligomeric species that induces apoptosis and cell death when applied to cells. Furthermore, the toxicity of the oligomeric $\alpha$-synuclein can be abolished by preventing the calcium influx through removal of extracellular calcium. This finding supports the fact that beta sheet rich oligomeric species are the most toxic species in cells, and that this toxicity is crucially dependent on calcium dysregulation. We have previously shown that the beta sheet rich oligomeric species (and not the monomeric species) generates reactive oxygen species 
resulting in oxidative stress (Cremades et al., 2012; Deas et al., 2015), and also that oligomeric species (and not monomeric species) can induce lipid peroxidation and cell death (Angelova et al., 2015). Therefore we hypothesise that the calcium dysregulation together with the increased levels of ROS induced by $\alpha$-synuclein oligomers act synergistically to result in cell toxicity. The monomeric induced calcium dysregulation is insufficient (without concomitant increase in reactive oxygen species) to induce cell death in this timeframe. Interestingly it has been reported that $\alpha$-synuclein cytotoxicity in a yeast model is mediated by the ability for $\alpha$-synuclein to increase the basal intracellular calcium levels (via a PMR1 mediated mechanism) and this results in an oxidative burst that ultimately kills cells. Abolishing the raised intracellular calcium prevented cell death in this model (Buttner et al., 2013). This model of $\alpha$-synuclein strongly resembles the effects of $\beta$-amyloid, which also is able to induce permeability of membranes and a calcium signal, which together with reactive oxygen species, can initiate cell death (Abramov et al., 2003).

In conclusion the combined data from calcium imaging in primary neurons exposed to $\alpha$ synuclein, and bilayer membrane experiments point us towards a unifying mechanism: increased levels of endogenous or exogenous $\alpha$-synuclein in its monomeric form can alter lipid permeability and induce calcium spiking and changes in basal calcium due to impaired efflux. During the aggregation process, conversion of the monomeric $\alpha$-synuclein to oligomeric $\alpha$-synuclein that has a beta sheet structure results in insertion of oligomeric $\alpha$ synuclein into membranes inducing ion channel formation and further calcium influx. Initially this may lead to dysfunction of calcium dependent mechanisms such as synaptic neurotransmission and plasticity. However, ultimately under conditions of altered clearance and buffering of calcium, the calcium dysregulation is sufficient to result in calcium dependent cell death and neurodegeneration. 


\section{Materials and Methods}

\section{Generation and characterisation of monomeric and oligomeric $\alpha$-synuclein}

The A90C mutant variant of $\alpha \mathrm{S}$ was expressed in, and purified from, E.coli as described previously (Hoyer et al., 2002a), and labelled with either maleimide-modified AF488 or AF647 dyes (Invitrogen), via the cysteine thiol moiety (at labelling efficiencies of $98 \pm 3 \%$ for both cases as estimated by mass spectrometry). The labelled protein was purified from the excess of free dye by a P10 desalting column with Sephadex G25 matrix (GE Healthcare), divided into aliquots, flash frozen and lyophilised; the lyophilised protein was stored at $-20^{\circ}$ C. Fluorescently-labelled oligomers (Method 1) were generated by using $1 \mathrm{mg} / \mathrm{ml}$ WT $\alpha \mathrm{S}$, AF647-labeled protein or equimolecular concentrations of AF488 and AF647-labeled protein $(1 \mathrm{mg} / \mathrm{ml}$ total protein concentration) in Tris $25 \mathrm{mM}, \mathrm{pH} 7.4,0.1 \mathrm{M} \mathrm{NaCl}$, with $0.01 \% \mathrm{NaN} 3$ to avoid bacterial growth during sample incubation. The samples were incubated in Eppendorf tubes at $37^{\circ} \mathrm{C}$ under constant shaking at $200 \mathrm{rpm}$. For the single-molecule FRET analysis of the fluorescently labelled oligomers, a $2 \mu \mathrm{L}$ aliquot was diluted $10^{5}$-fold by serial dilution with $0.022 \mu \mathrm{m}$-filtered Tris $25 \mathrm{mM}, \mathrm{pH} 7.4,0.1 \mathrm{M} \mathrm{NaCl}$. Glass slides were incubated for $1 \mathrm{~h}$ with BSA at $1 \mathrm{mg} / \mathrm{mL}$ to prevent $\alpha$-S species from adsorbing to the surface, as we have recently shown (Cremades et al., 2012). Immediately after removal of the BSA solution, $500 \mu \mathrm{L}$ of diluted sample was placed on the slide for analysis.

Method 2: Human $\alpha \mathrm{S}$ was overexpressed and purified as a monomeric fraction from E.coli as described previously (Hoyer et al., 2002b). Samples of $\alpha-S$ oligomers were prepared by incubating monomeric protein at ca. $800 \mu \mathrm{M}(12 \mathrm{mg} / \mathrm{ml})$ in $\mathrm{PBS}$ at $37^{\circ} \mathrm{C}$ without agitation for 18-22 h. To get this high concentration of protein, a solution of monomeric $\alpha \mathrm{S}$ in miliQ water was lyophilized and typically $6 \mathrm{mg}$ of lyophilized $\alpha \mathrm{S}$ was resuspended in $500 \mu \mathrm{l}$ of PBS 
buffer. The resulting solution was passed through a filter device with a $0.22 \mu \mathrm{m}$ cut-off to remove any particles of dust and/or large protein aggregates that could have been formed during the lyophilization process. After incubating this solution at $37^{\circ} \mathrm{C}$, without agitation, for $18-22 \mathrm{~h}$, most of the protein remains monomeric, but a fraction of ca. $5 \%$ of the protein is in the form of aggregates. These aggregates are still soluble after ultracentrifugation at 90,000 rpm for $1 \mathrm{~h}$. In order to isolate these aggregates from the monomeric protein, a series of filtering devices with a $100 \mathrm{kDa}$ cut-off were used, so that the monomeric protein passed through the membrane while oligomeric species bigger than $100 \mathrm{kDa}$ remained at the top of the filter.

\section{Characterization of $\alpha$-synuclein in planar lipid bilayers}

Phospholipids 1,2-dioleoyl-sn-glycero-3-phosphocholine (DOPC) and cardiolipin were obtained from Avanti Polar Lipids (Alabaster, AL). Planar BLM were formed from a 20 $\mathrm{mg} / \mathrm{ml}$ lipid solution of either DOPC or DOPC:Cardiolipin (3:1) in n-decane (Aldrich) as it has been shown previously (Abramov et al., 2011). The solution was painted across the 200 $\mu \mathrm{m}$ aperture of a Delrin cup (Warner Instruments, Hamden, CT). Both cis (voltage command side) and trans (virtual ground) compartments of the cuvette contained HBSS solution containing $5.3 \mathrm{mM} \mathrm{KCl}, 138 \mathrm{mM} \mathrm{NaCl}, 1 \mathrm{mM} \mathrm{CaCl}_{2}, 0.4 \mathrm{mM} \mathrm{KH}_{2} \mathrm{PO}_{4}, 0.3 \mathrm{mM} \mathrm{Na}_{2} \mathrm{HPO}_{4}$, $4.2 \mathrm{mM} \mathrm{NaHCO}$. $100 \mathrm{nM}$ of $\alpha$-synuclein was added to the cis compartment of the cuvette. All measurements were performed at room temperature.

For the measurements of the selectivity of the induced conductance reversal potential (zero current potential) was measured in a presence of 10:1 (trans-to-cis) transmembrane ion gradient. In these experiments membranes were form between compartments containing: (cis) $15 \mathrm{mM} \mathrm{NaCl}, 2 \mathrm{mM} \mathrm{CaCl} 2,10 \mathrm{mM}$ Tris-HCl pH 7.4 / (trans) $150 \mathrm{mM} \mathrm{NaCl}, 2 \mathrm{mM} \mathrm{CaCl} 2,10$ 
$\mathrm{mM}$ Tris- $\mathrm{HCl} \mathrm{pH}$ 7.4. The liquid junction potential offset was compensated for prior to the membrane formation.

Currents across the bilayer were recorded using Planar Lipid Bilayer Workstation (Warner Instruments). The cis compartment was connected to the head stage input and the trans compartment was held at virtual ground via a pair of matched $\mathrm{Ag} / \mathrm{AgCl}$ electrodes. Signals from voltage-clamped BLM were high-pass-filtered at $2.1 \mathrm{kHz}$ using an eight-pole Bessel filter LPF-8 (Warner Instruments), digitized using Data Translation Digitizer and recorded on PC using in-house software.

\section{Cell culture}

Mixed cultures of hippocampal or cortical neurons and glial cells were prepared as described previously (Vaarmann et al., 2010) with modifications, from Sprague-Dawley rat pups 2-4 days post-partum (UCL breeding colony). Experimental procedures were performed in full compliance with the United Kingdom Animal (Scientific Procedures) Act of 1986. Hippocampi and cortex were removed into ice-cold PBS $\left(\mathrm{Ca}^{2+}, \mathrm{Mg}^{2+}\right.$-free, Invitrogen, Paisley, UK). The tissue was minced and trypsinised $\left(0.25 \%\right.$ for $5 \mathrm{~min}$ at $\left.37^{\circ} \mathrm{C}\right)$, triturated and plated on poly-D-lysine-coated coverslips and cultured in Neurobasal A medium (Invitrogen, Paisley, UK) supplemented with B-27 (Invitrogen, Paisley, UK) and 2 mM Lglutamine. Cultures were maintained at $37^{\circ} \mathrm{C}$ in a humidified atmosphere of $5 \% \mathrm{CO}_{2}$ and 95\% air, fed twice a week and maintained for a minimum of 12 days before experimental use to ensure expression of glutamate and other receptors. Neurons were easily distinguishable from glia: they appeared phase bright, had smooth rounded somata and distinct processes, and lay just above the focal plane of the glial layer. Cells were used at 12-15 days in vivo (DIV). 


\section{Acute brain slices.}

Horizontal hippocampus/entorhinal cortex slices $(100 \mu \mathrm{m})$ were prepared from P9 Wistar rats, using standard procedures. Tissue was sliced at $\sim 4{ }^{\circ} \mathrm{C}$ in artificial cerebrospinal fluid (in mm: $\mathrm{NaCl}, 129 ; \mathrm{NaH} 2 \mathrm{PO} 4,1.25 ;$ glucose, 10; $\mathrm{MgSO} 4,1.8 ; \mathrm{CaCl} 2,1.6 ; \mathrm{KCl}, 3 ; \mathrm{NaHCO}$, 26, pH 7.4) continuously bubbled with $95 \%$ O2/5\% CO2. Slices were imaged in HBSS for up to $3 \mathrm{~h}$ after preparation.

\section{Imaging $\left[\mathrm{Ca}^{2+}\right]_{\mathrm{c}}$}

Primary neurons and astrocytes were loaded for $30 \mathrm{~min}$ at room temperature with $5 \mu \mathrm{M}$ fura-2 AM or fluo-4 AM and $0.005 \%$ Pluronic in a HEPES-buffered salt solution (HBSS) composed (mM): $156 \mathrm{NaCl}, 3 \mathrm{KCl}, 2 \mathrm{MgSO}_{4}, 1.25 \mathrm{KH}_{2} \mathrm{PO}_{4}, 2 \mathrm{CaCl}_{2}, 10$ glucose and $10 \mathrm{HEPES}, \mathrm{pH}$ adjusted to 7.35 with $\mathrm{NaOH}$. $\mathrm{Ca}^{2+}$-free medium contained $0.5 \mathrm{mM}$ EGTA.

Fluorescence measurements were obtained on an epifluorescence inverted microscope equipped with a 20x fluorite objective. $\left[\mathrm{Ca}^{2+}\right]_{\mathrm{c}}$ was monitored in single cells using excitation light provided by a Xenon arc lamp, the beam passing monochromator at 340, 360 and 380 nm (Cairn Research, Kent, UK). Emitted fluorescence light was reflected through a $515 \mathrm{~nm}$ long-pass filter to a cooled CCD camera (Retiga, QImaging, Canada) and digitised to 12 bit resolution. All imaging data were collected and analysed using software from Andor (Belfast, UK). Fura-2 is a ratiometric dye with a high affinity for calcium and this allows an accurate measurement of the cytosolic calcium independent of loading variations. The experimental setup used for measuring fura- 2 also enables signals with transient rapid kinetics and decay times to be measured. The measurement of this dye is a ratio between the emitted light at 340nm (high calcium) and the emitted light at 380nm (low calcium). The Fura-2 data have 
not been calibrated in terms of $\left[\mathrm{Ca}^{2+}\right]_{\mathrm{c}}$ because of the uncertainty arising from the use of different calibration techniques.

Confocal images were obtained using a Zeiss 710 CLSM equipped with a 40x oil immersion objective. The $488 \mathrm{~nm}$ Argon laser line was used to excite fluo-4 which was measured between $510-550 \mathrm{~nm}$. Illumination intensity was kept to a minimum (at $0.1-0.2 \%$ of laser output) to avoid phototoxicity and the pinhole set to give an optical slice of $\sim 2 \mu \mathrm{m}$. All data presented were obtained from at least 5 coverslips and 2-3 different cell preparations. Fluo-4, in contrast is a single wave calcium sensor where the emission intensity depends on the levels of bound calcium. It has a lower $\mathrm{Kd}$ and is useful for visualising calcium variations around the basal concentration. As fluo-4 intensity is measured on the confocal microscope, the units used for these experiments are (arbitrary) fluorescence units.

\section{Toxicity Experiments}

For toxicity assays we loaded cells simultaneously with $20 \mu \mathrm{M}$ propidium iodide (PI), which is excluded from viable cells but exhibits a red fluorescence following a loss of membrane integrity, and $4.5 \mu \mathrm{M}$ Hoechst 33342 (Molecular Probes, Eugene, OR), which gives a blue staining to chromatin, to count the total number of cells. Using phase contrast optics, a bright field image allowed identification of neurones, which look quite different to the flatter glial component and also lie in a different focal plane, above the glial layer. A total number of 600-800 neurones or glial cells were counted in 10 fields of each coverslip. Each experiment was repeated five or more times using separate cultures.

\section{Caspase-3 activity assay}

For measurements of caspase- 3 activation cells were loaded for $15 \mathrm{~min}$ at room temperature with $10 \mu \mathrm{M}$ NucView 488 caspase-3 substrate (Biotium, USA) in HBSS. NucView 488 is a 
novel class of enzyme substrates for real-time detection of caspase-3 activity in live cells. The substrate can rapidly cross cell membrane to enter the cell cytoplasm, where it is cleaved by caspase-3 to release the high-affinity DNA dye. The released DNA dye migrates to the cell nucleus to stain the nucleus brightly green.

Confocal images were obtained using Zeiss 710 confocal laser scanning microscope and a 40x oil immersion objective. The $488 \mathrm{~nm}$ argon laser was used to excite NucView 488 fluorescence, which was measured using a bandpass filter from 510 and $560 \mathrm{~nm}$.

\section{Statistical analysis}

Statistical analysis and exponential curve fitting were performed using Origin 9 (Microcal Software Inc., Northampton, MA) software. Results are expressed as means \pm standard error of the mean (S.E.M.). Student's t-test are performed where appropriate and p values provided in results section. 


\section{Acknowledgments}

This work was supported by the Wellcome/MRC Parkinson's Disease Consortium grant to UCL/IoN, the University of Sheffield and the MRC Protein Phosphorylation Unit at the University of Dundee (grant number WT089698), the Leverhulme Trust. SG is a Wellcome Trust Intermediate Clinical Fellow. The work was undertaken at University College London Hospitals (UCLH) and University College London (UCL), who receives support from the Department of Health's NIHR Biomedical Research Centre's funding streams.

\section{Potential Conflicts of Interest}

The authors declare no conflict of interest. 
Reference List

Abramov, A. Y., Canevari, L. and Duchen, M. R. (2003). Changes in intracellular calcium and glutathione in astrocytes as the primary mechanism of amyloid neurotoxicity. J. Neurosci. 2003. Jun. 15. ;23(12. ):5088. -95. 23, 5088-5095.

Abramov, A. Y., lonov, M., Pavlov, E. and Duchen, M. R. (2011). Membrane cholesterol content plays a key role in the neurotoxicity of beta-amyloid: implications for Alzheimer's disease. Aging Cell 10, 595-603.

Angelova, P. R., Horrocks, M. H., Klenerman, D., Gandhi, S., Abramov, A. Y. and Shchepinov, M. S. (2015). Lipid peroxidation is essential for alpha-synuclein-induced cell death. J. Neurochem. $133,582-589$.

Buttner, S., Faes, L., Reichelt, W. N., Broeskamp, F., Habernig, L., Benke, S., Kourtis, N., Ruli, D., Carmona-Gutierrez, D., Eisenberg, T. et al. (2013). The Ca2+/Mn2+ ion-pump PMR1 links elevation of cytosolic $\mathrm{Ca}(2+)$ levels to alpha-synuclein toxicity in Parkinson's disease models. Cell Death. Differ. 2013. Mar. ;20. (3):465. -77. doi. : 10. 1038. /cdd. 2012. 142. Epub. 2012. Nov. 16. 20, 465-477.

Chen, S. W., Drakulic, S., Deas, E., Ouberai, M., Aprile, F. A., Arranz, R., Ness, S., Roodveldt, C., Guilliams, T., De-Genst, E. J. et al. (2015). Structural characterization of toxic oligomers that are kinetically trapped during alpha-synuclein fibril formation. Proc. Natl. Acad. Sci. U. S. A 112, E1994-E2003.

Cookson, M. R. (2009). alpha-Synuclein and neuronal cell death. Mol. Neurodegener. 2009. Feb. 4;4:9. doi. : 10. 1186. /1750. -1326. -4-9. 4, 9.

Cremades, N., Cohen, S. I., Deas, E., Abramov, A. Y., Chen, A. Y., Orte, A., Sandal, M., Clarke, R. W., Dunne, P., Aprile, F. A. et al. (2012). Direct observation of the interconversion of normal and toxic forms of alpha-synuclein. Cell. 2012. May. 25. ;149. (5):1048. -59. doi. : 10. 1016. /j. cell. 2012. 03. 037. 149, 1048-1059.

Danzer, K. M., Haasen, D., Karow, A. R., Moussaud, S., Habeck, M., Giese, A., Kretzschmar, H., Hengerer, B. and Kostka, M. (2007). Different species of alpha-synuclein oligomers induce calcium influx and seeding. J. Neurosci. 2007. Aug. 22. ;27. (34. ):9220. -32. 27, 9220-9232.

Deas, E., Cremades, N., Angelova, P. R., Ludtmann, M., Yao, Z., Chen, S., Horrocks, M., Banushi, B., Little, D., Devine, M. et al. (2015). Alpha-synuclein oligomers interact with metal ions to induce oxidative stress and neuronal death in Parkinson's disease. Antioxid. Redox Signal.

Desplats, P., Lee, H. J., Bae, E. J., Patrick, C., Rockenstein, E., Crews, L., Spencer, B., Masliah, E. and Lee, S. J. (2009). Inclusion formation and neuronal cell death through neuron-to-neuron transmission of alpha-synuclein. Proc. Natl. Acad. Sci. U. S. A. 2009. Aug. 4;106. (31. ):13010. -5. doi. : 10. 1073. /pnas. 0903691106. Epub. 2009. Jul. 27. 106, 13010-13015.

Domijan, A. M., Kovac, S. and Abramov, A. Y. (2014). Lipid peroxidation is essential for phospholipase $\mathrm{C}$ activity and the inositol-trisphosphate-related $\mathrm{Ca}(2)(+)$ signal. J. Cell Sci. 127, 21-26. 
Follett, J., Darlow, B., Wong, M. B., Goodwin, J. and Pountney, D. L. (2013). Potassium depolarization and raised calcium induces alpha-synuclein aggregates. Neurotox. Res. 23, 378-392.

Hansen, C., Angot, E., Bergstrom, A. L., Steiner, J. A., Pieri, L., Paul, G., Outeiro, T. F., Melki, R., Kallunki, P., Fog, K. et al. (2011). alpha-Synuclein propagates from mouse brain to grafted dopaminergic neurons and seeds aggregation in cultured human cells. J. Clin. Invest. 2011. Feb. ;121. (2):715. -25. doi. : 10. 1172. /JCI43366. Epub. 2011. Jan. 18. 121, 715-725.

Hoyer, W., Antony, T., Cherny, D., Heim, G., Jovin, T. M. and Subramaniam, V. (2002a). Dependence of alpha-synuclein aggregate morphology on solution conditions. J. Mol. Biol. 2002. Sep. 13;322. (2):383. -93. 322, 383-393.

Hoyer, W., Antony, T., Cherny, D., Heim, G., Jovin, T. M. and Subramaniam, V. (2002b). Dependence of alpha-synuclein aggregate morphology on solution conditions. J. Mol. Biol. 2002. Sep. 13;322. (2):383. -93. 322, 383-393.

Kalia, L. V., Kalia, S. K., McLean, P. J., Lozano, A. M. and Lang, A. E. (2013). alpha-Synuclein oligomers and clinical implications for Parkinson disease. Ann. Neurol. 2013. Feb. ;73. (2):155. -69. doi. : 10. 1002. /ana. 23746. Epub. 2012. Dec. 7. 73, 155-169.

Kayed, R., Sokolov, Y., Edmonds, B., McIntire, T. M., Milton, S. C., Hall, J. E. and Glabe, C. G. (2004). Permeabilization of lipid bilayers is a common conformation-dependent activity of soluble amyloid oligomers in protein misfolding diseases. J. Biol. Chem. 2004. Nov. 5;279. 145. ):46363. -6. Epub. 2004. Sep. 21. 279, 46363-46366.

Nath, S., Goodwin, J., Engelborghs, Y. and Pountney, D. L. (2011). Raised calcium promotes alphasynuclein aggregate formation. Mol. Cell Neurosci. 46, 516-526.

Quist, A., Doudevski, I., Lin, H., Azimova, R., Ng, D., Frangione, B., Kagan, B., Ghiso, J. and Lal, R. (2005). Amyloid ion channels: a common structural link for protein-misfolding disease. Proc. Natl. Acad. Sci. U. S. A. 2005. Jul. 26. ;102. (30. ):10427. -32. Epub. 2005. Jul. 14. 102, 1042710432.

Sokolov, Y., Kozak, J. A., Kayed, R., Chanturiya, A., Glabe, C. and Hall, J. E. (2006). Soluble amyloid oligomers increase bilayer conductance by altering dielectric structure. J. Gen. Physiol. 2006. Dec. ;128. (6. ):637. -47. Epub. 2006. Nov. 13. 128, 637-647.

Vaarmann, A., Gandhi, S., Gourine, A. V. and Abramov, A. Y. (2010). Novel pathway for an old neurotransmitter: dopamine-induced neuronal calcium signalling via receptor-independent mechanisms. Cell Calcium. 2010. Aug. -Sep. ;48. (2-3):176. -82. doi. : 10. 1016. /j. ceca. 2010. 08. 008. Epub. 2010. Sep. 16. 48, 176-182.

Volles, M. J. and Lansbury, P. T., Jr. (2002). Vesicle permeabilization by protofibrillar alpha-synuclein is sensitive to Parkinson's disease-linked mutations and occurs by a pore-like mechanism. Biochemistry. 2002. Apr 9. ;41. (14):4595. -602. 41, 4595-4602.

Volles, M. J., Lee, S. J., Rochet, J. C., Shtilerman, M. D., Ding, T. T., Kessler, J. C. and Lansbury, P. T., Jr. (2001). Vesicle permeabilization by protofibrillar alpha-synuclein: implications for the pathogenesis and treatment of Parkinson's disease. Biochemistry. 2001. Jul. 3;40. (26. ):7812. -9. 40, 7812-7819. 
Volpicelli-Daley, L. A., Luk, K. C., Patel, T. P., Tanik, S. A., Riddle, D. M., Stieber, A., Meaney, D. F., Trojanowski, J. Q. and Lee, V. M. (2011). Exogenous alpha-synuclein fibrils induce Lewy body pathology leading to synaptic dysfunction and neuron death. Neuron. 2011. Oct. 6. ;72. (1):57. -71. doi. : 10. 1016. /j. neuron. 2011. 08. 033. 72, 57-71.

Winner, B., Jappelli, R., Maji, S. K., Desplats, P. A., Boyer, L., Aigner, S., Hetzer, C., Loher, T., Vilar, M., Campioni, S. et al. (2011). In vivo demonstration that alpha-synuclein oligomers are toxic. Proc. Natl. Acad. Sci. U. S. A. 2011. Mar. 8. ;108. (10):4194. -9. doi. : 10. 1073. /pnas. 1100976108. Epub. 2011. Feb. 15. 108, 4194-4199.

Zakharov, S. D., Hulleman, J. D., Dutseva, E. A., Antonenko, Y. N., Rochet, J. C. and Cramer, W. A. (2007). Helical alpha-synuclein forms highly conductive ion channels. Biochemistry. 2007. Dec. 18. ;46. (50. ):14369. -79. Epub. 2007. Nov. 22. 46, 14369-14379. 


\section{Figures}

A

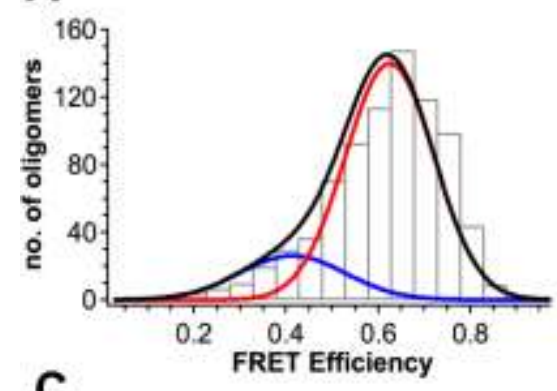

C

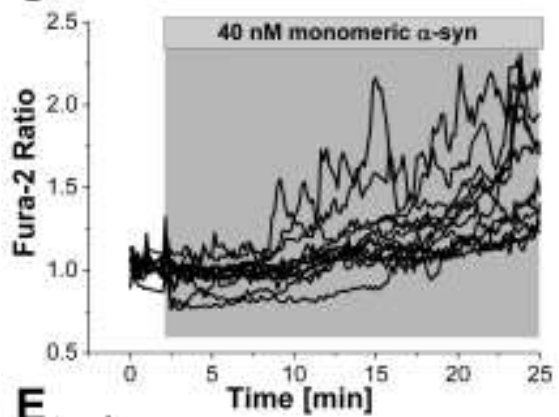

E
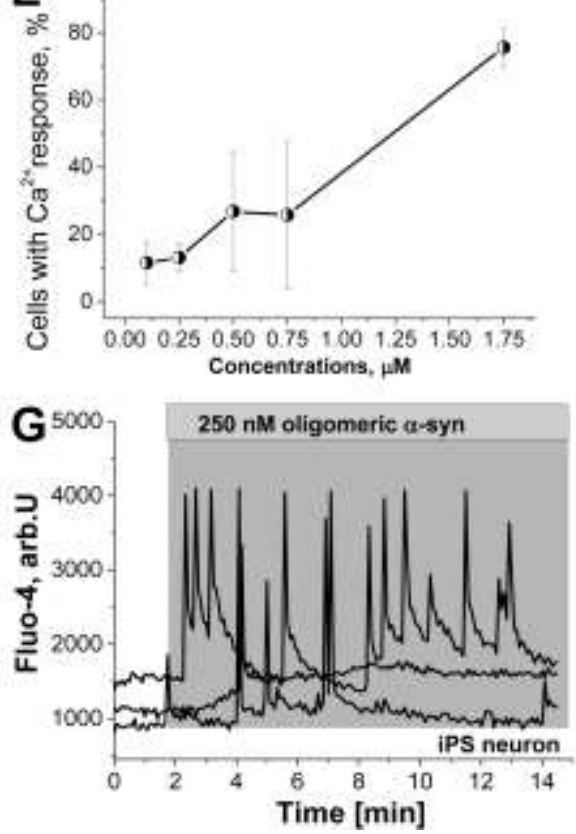

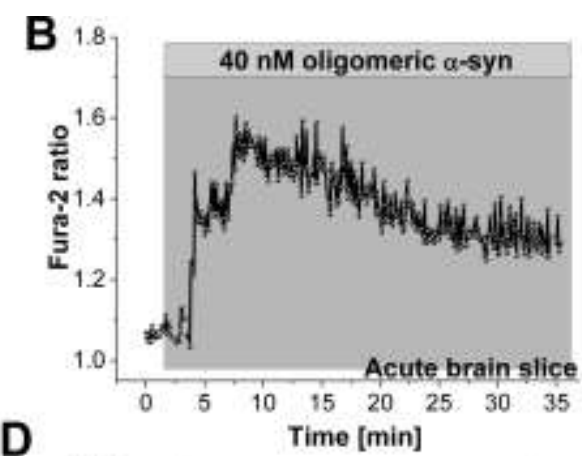

D

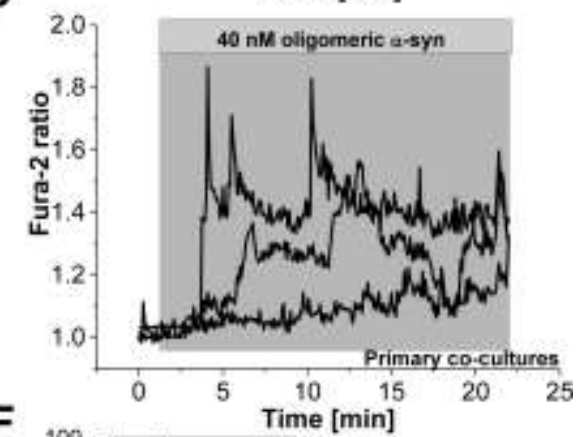

$\mathbf{F}$

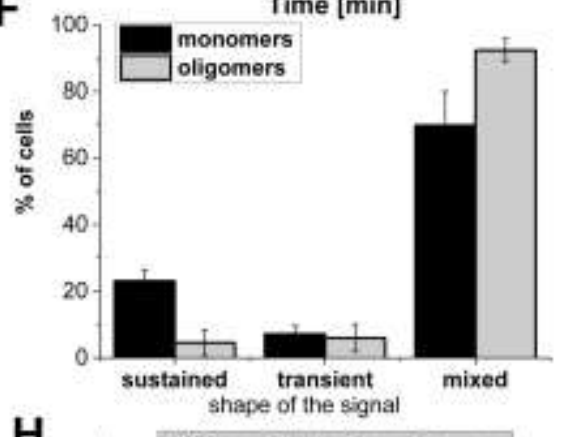

H

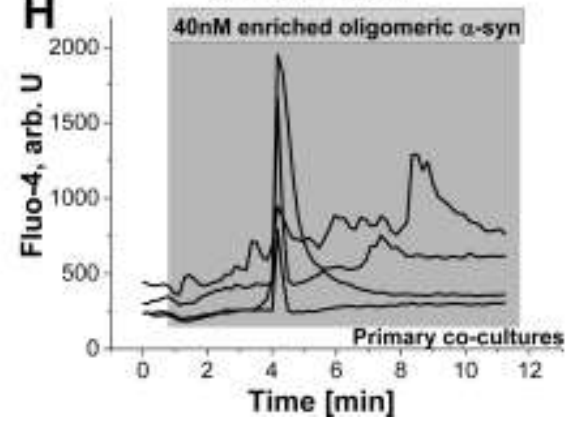

Figure 1: Application of extracellular $\alpha$-synuclein induces a cytosolic calcium signal. 
(A) shows a characteristic single-molecule FRET histogram of the $29 \mathrm{~h}$ time-point used in this study. There are both globular non-toxic $(18 \%, \mathrm{E}=0.41)$, and toxic, $\beta$-sheet containing oligomers $(82 \%, \mathrm{E}=0.62)$ present. Application of 40nM oligomeric $\alpha$-synuclein induces a calcium signal in an acute rat brain slice (B). 40nM monomeric (C) or oligomeric (D) $\alpha$ synuclein induced elevation of cytosolic calcium signal in primary neurons and astrocytes. Both forms of $\alpha$-synuclein induced a rise in basal cytosolic calcium as well as calcium spikes. Dose response experiment demonstrating the number of cells responding at different concentrations of oligomeric $\alpha$-synuclein (E). Histogram demonstrating the proportion of cells exhibiting each pattern of calcium signal (F). The $\alpha$-synuclein induced calcium signal was also observed in neurons derived from iPSCs (G). Enriched oligomeric $\alpha$-synuclein induced a rise in basal cytosolic calcium as well as calcium spikes $(\mathrm{H})$. 
A

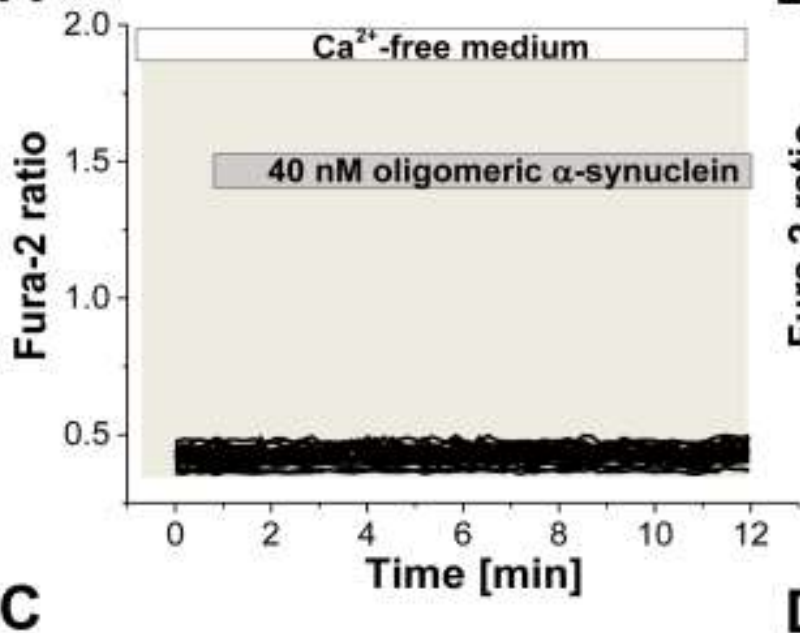

$40 \mathrm{nM}$ oligomeric $\alpha$-synuclein
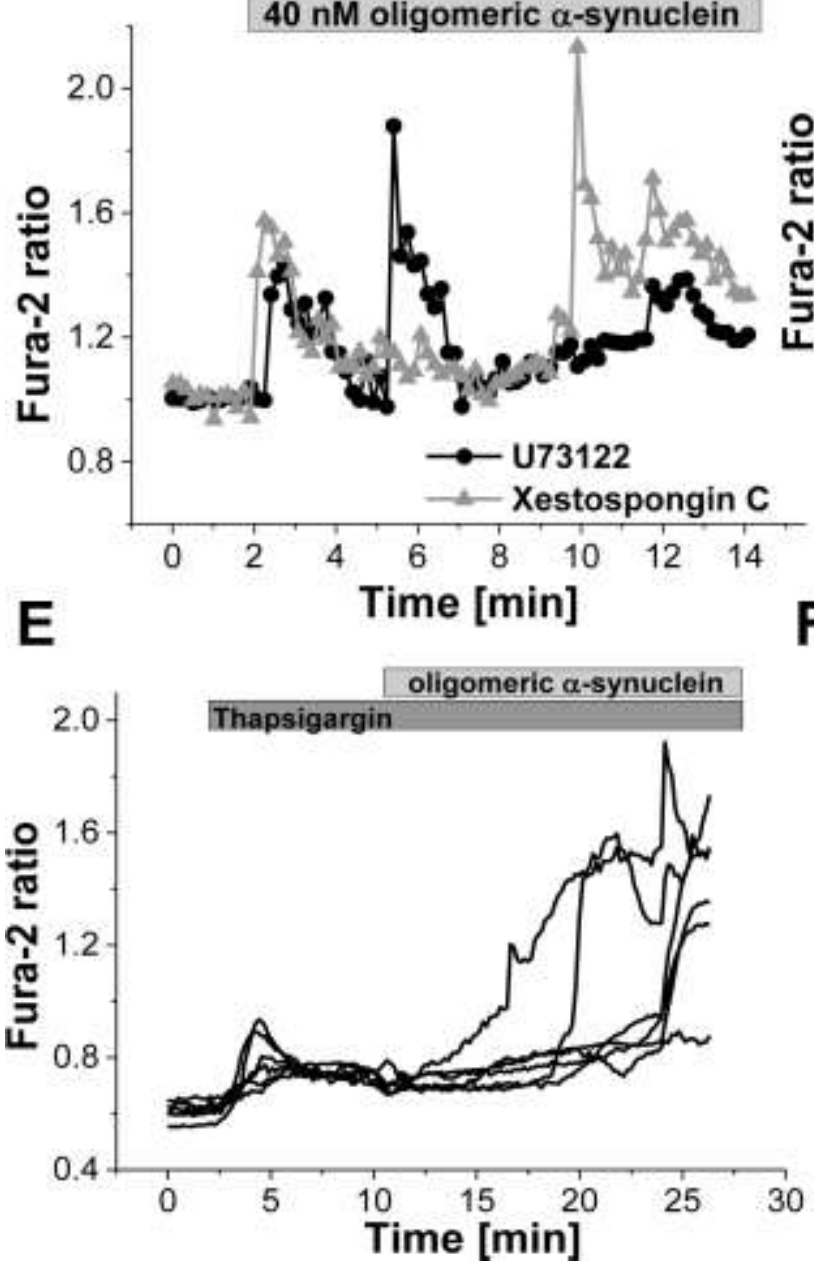

B
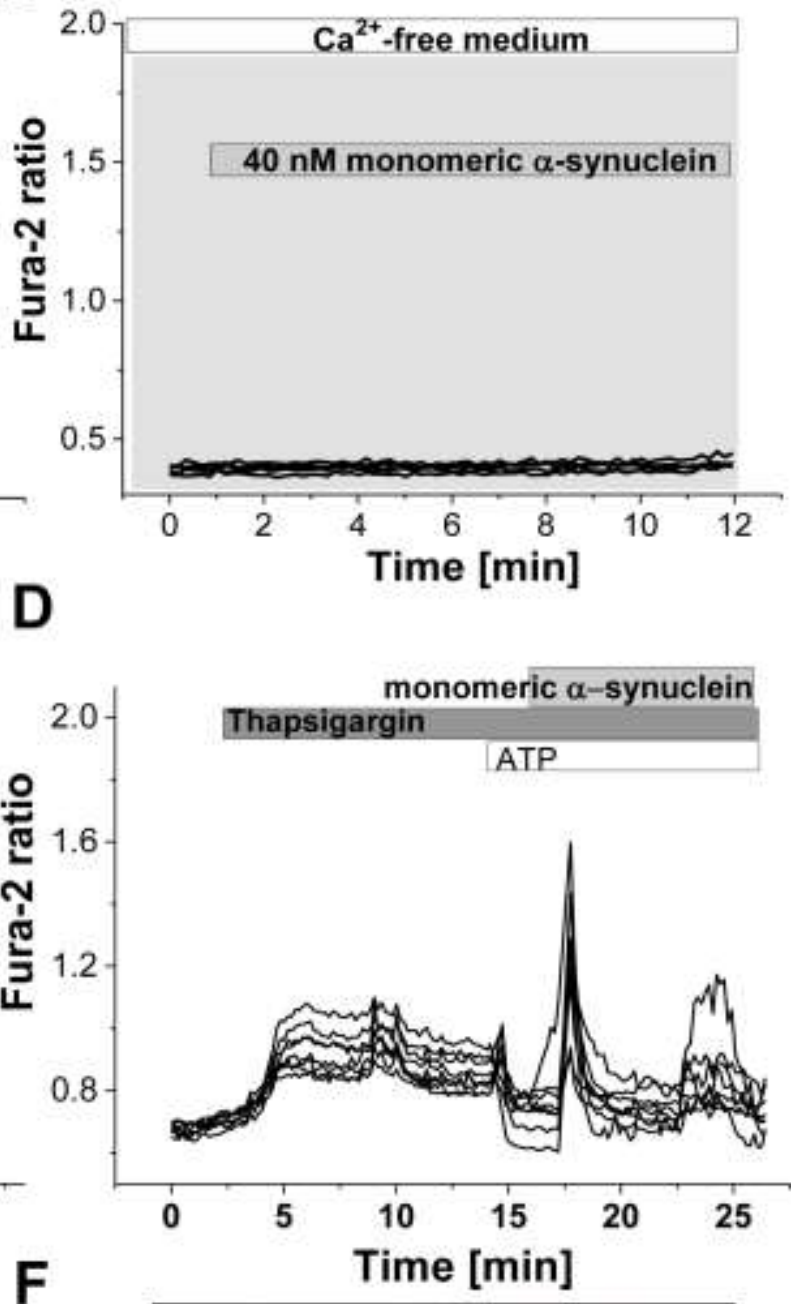

$\mathbf{F}$

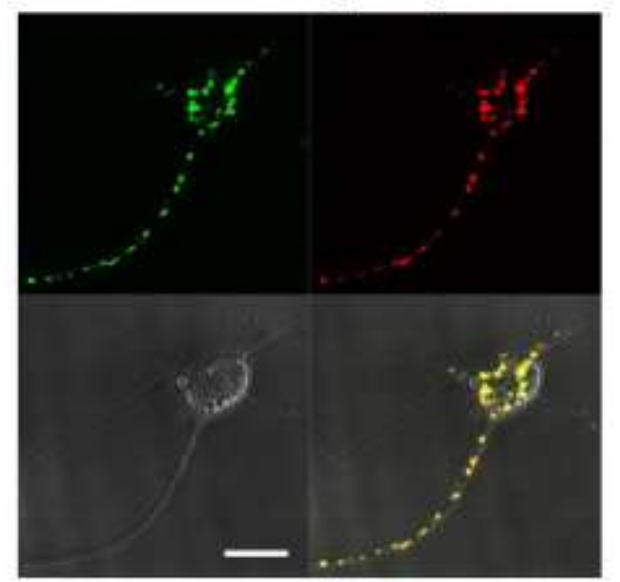

Figure 2: Identification of the source of the $\alpha$-synuclein induced calcium signal. 
Both monomeric and oligomeric calcium signals could be prevented completely by removal of calcium from the extracellular media (A) and (B). Inhibition of PLC by U73122 and inhibition of IP3 receptors by Xestospongin $\mathrm{C}$ had no effect on the $\alpha$-synuclein induced calcium signal (C). Depletion of the ER calcium store using thapsigargin did not affect the monomeric or oligomeric induced calcium signal $(\mathbf{D}, \mathbf{E}) .(\mathbf{F})$ is representative image of single neuron following application of equimolar ratio of monomeric AF-488 (green) and AF-647 (red) labelled $\alpha$-synuclein demonstrating intracellular uptake of recombinant $\alpha$-synuclein species. 

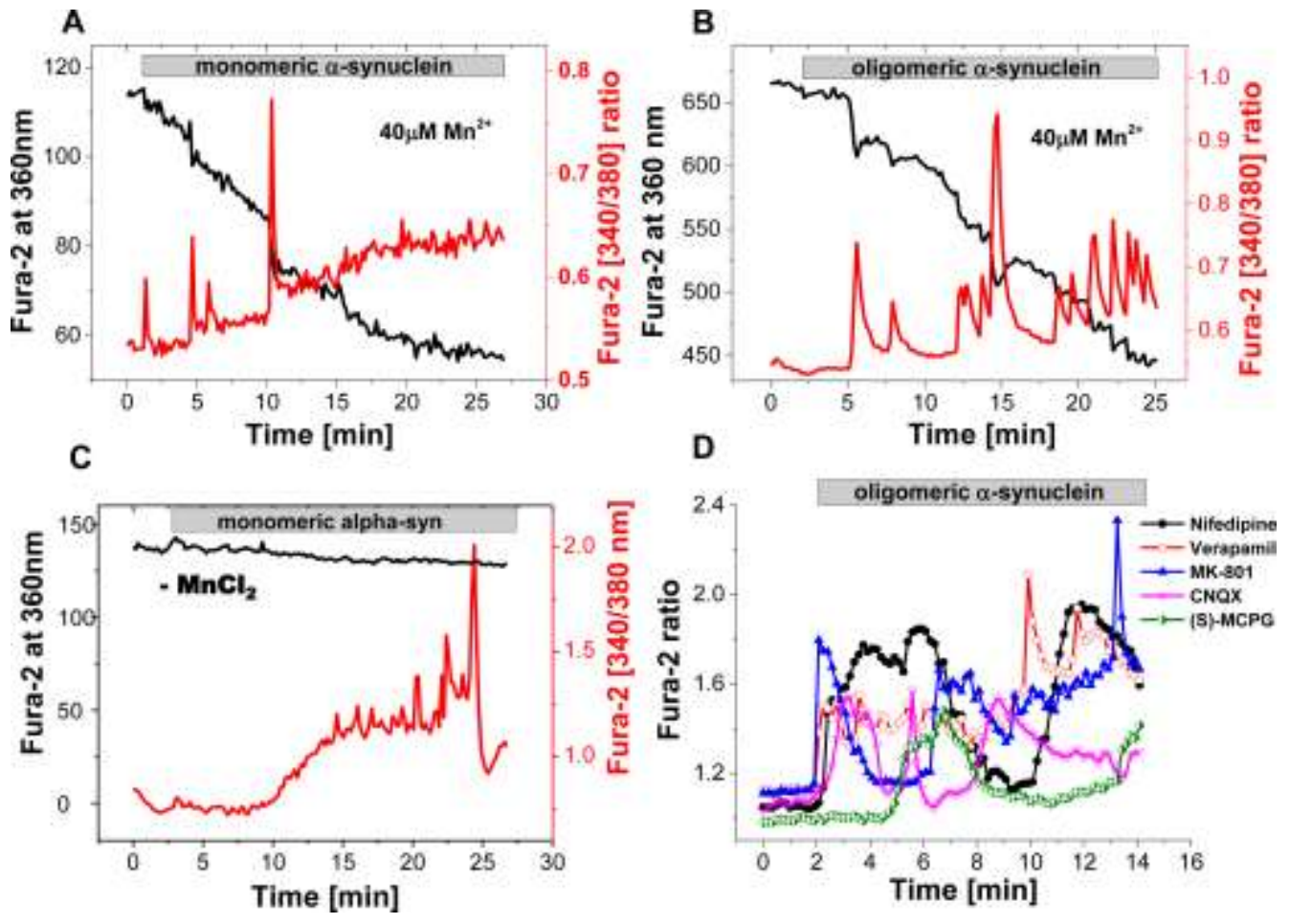

Figure 3: Manganese $\left(\mathrm{Mn}^{2+}\right)$ quench assay confirms that $\alpha$-synuclein-induced $\mathrm{Ca}^{2+}$ transients originate from a $\mathrm{Ca}^{2+}$ influx across plasmalemmal membrane.

Fura-2 loaded neurons showed typical $\left[\mathrm{Ca}^{2+}\right]_{\mathrm{c}}$ fluctuations in response to monomeric (A) or oligomeric (B) $\alpha$-synuclein. With the addition of $40 \mu \mathrm{M} \mathrm{Mn}{ }^{2+}$ each $\left[\mathrm{Ca}^{2+}\right]_{\mathrm{c}}$ transient was accompanied by a step quench of the $360 \mathrm{~nm}$ fura- 2 signal, confirming that each transient reflects a pulsed influx of divalent cations seen in response to $\alpha$-synuclein. Application of monomeric $\alpha$-synuclein in the absence of manganese chloride did not induce any alteration in the fura-2 360nm signal (C). The $\alpha$-synuclein induced $\mathrm{Ca}^{2+}$ influx was independent of the presence of inhibitors of plasmalemmal channels $20 \mu \mathrm{M}$ verapamil, $1 \mu \mathrm{M}$ Nifedipine, $10 \mu \mathrm{M}$ MK-801, $20 \mu \mathrm{M}$ CNQX or $50 \mu \mathrm{M}$ (S)-MCPG (D). 
A
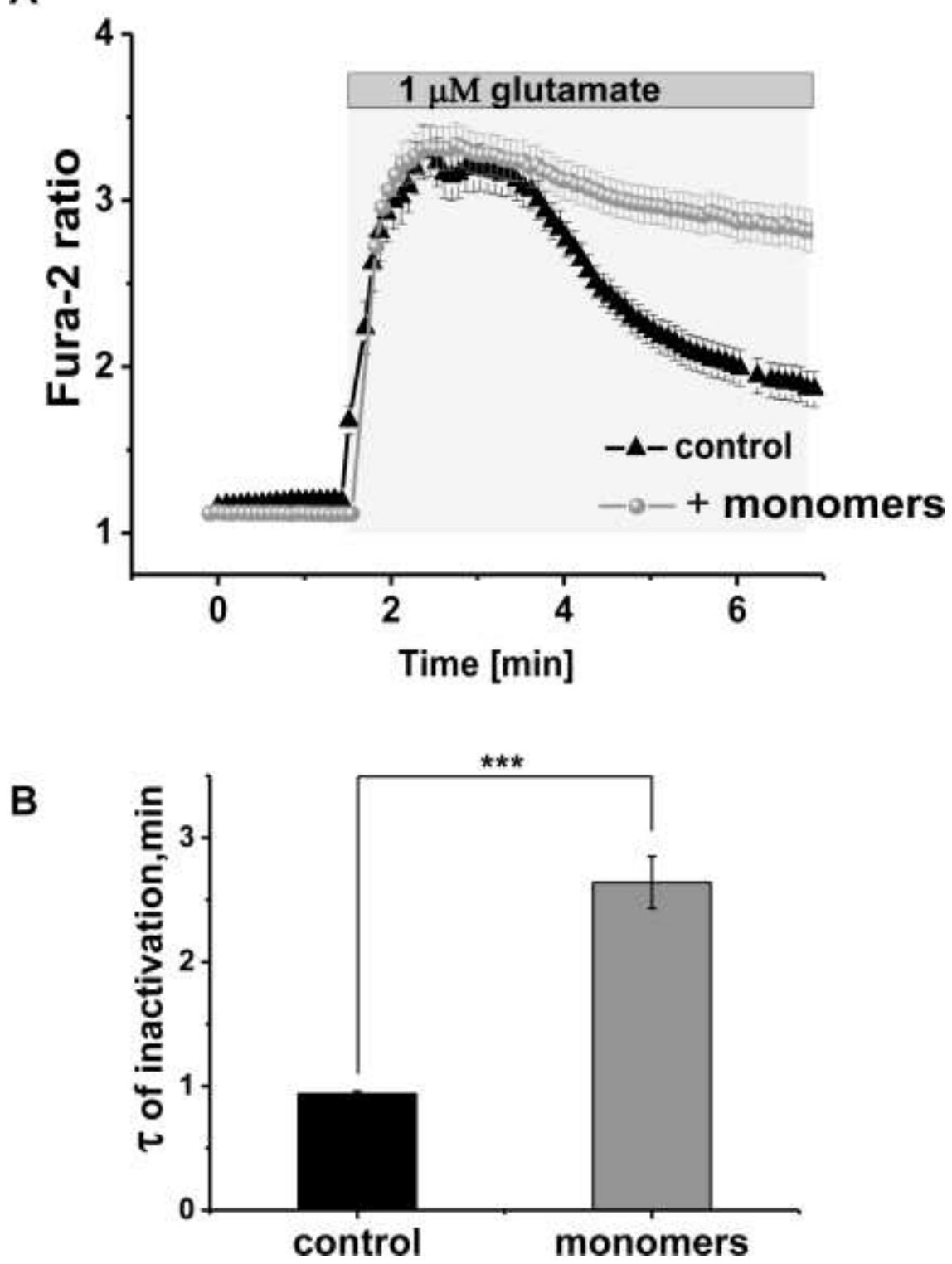

Figure 4: Monomeric $\alpha$-synuclein leads to impairment of calcium efflux.

Application of 5uM glutamate to cells pre-incubated with $\alpha$-synuclein monomers (A) resulted in significantly delayed recovery of the cytosolic calcium signal (over a period of 10mins) compared to control (recovery within 2 minutes, B). 

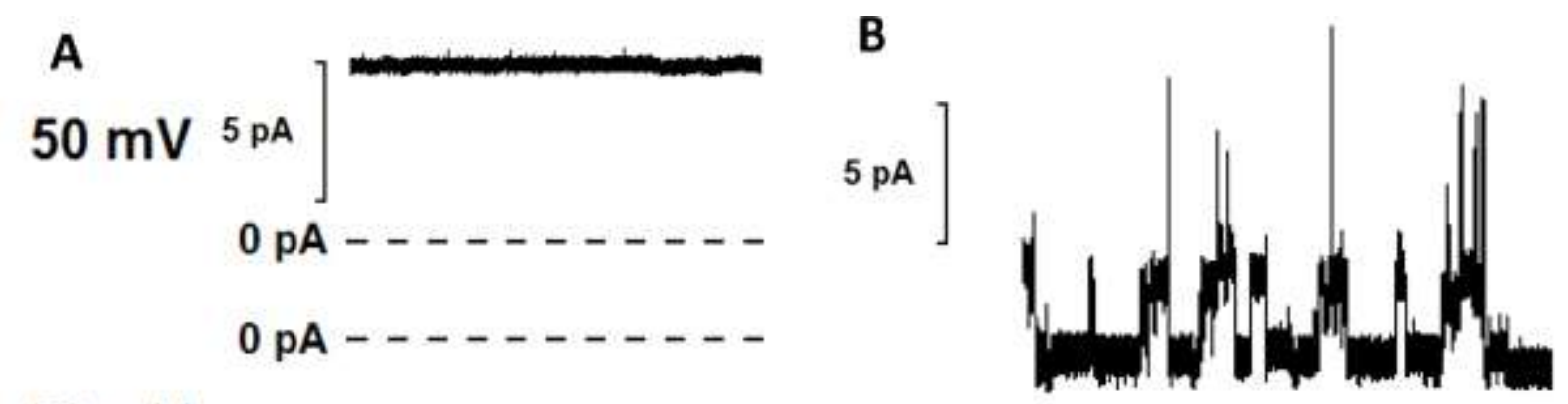

$-50 \mathrm{mV}$
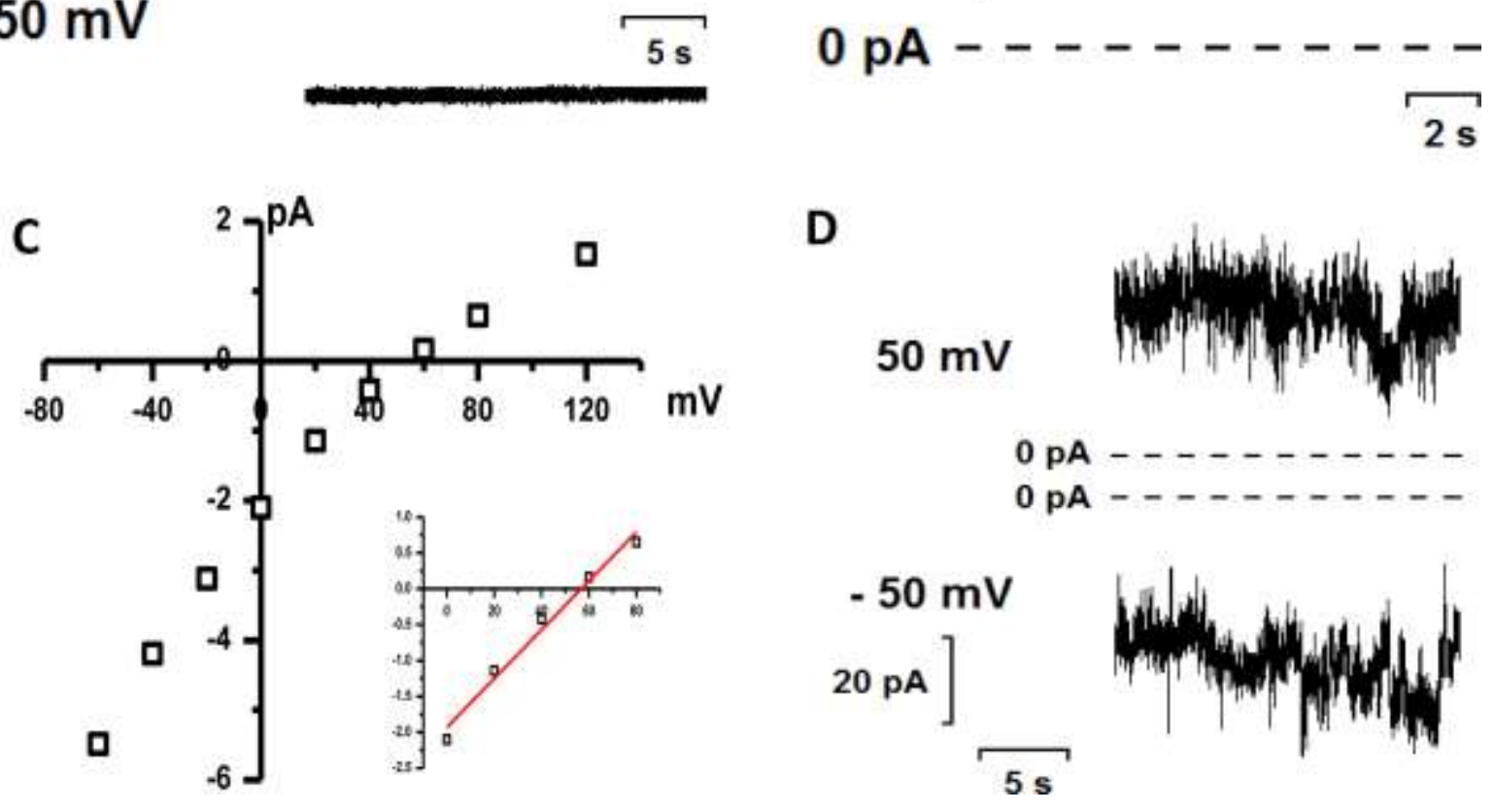

\section{Figure 5: Channel activity of $\alpha$-synuclein on artificial membranes}

(A) Oligomeric $\alpha$-synuclein was added to the cis compartment of the bilayer cuvette to a final concentration of $100 \mathrm{nM}$. The membrane was suspended between symmetric HBSS supplemented with $1 \mathrm{mM} \mathrm{CaCl}_{2}$. (B) Channels induced by $100 \mathrm{nM}$ oligomer $\alpha$-synuclein in lipid bilayers suspended between aqueous solution of $15 \mathrm{mM} \mathrm{NaCl}$ (cis)/150 mM NaCl (trans), $2 \mathrm{mM} \mathrm{CaCl} 2,10 \mathrm{mM}$ Tris $\mathrm{pH} 7.4$ (symmetric). Voltage of $150 \mathrm{mV}$ was applied across BLM. (C) Current-voltage dependence of the channels presented panel B. (D) Irregular currents induced by $100 \mathrm{nM}$ of monomeric $\alpha$-synuclein in BLM. Membrane was suspended between symmetric HBSS supplemented with $1 \mathrm{mM} \mathrm{CaCl}_{2}$. 


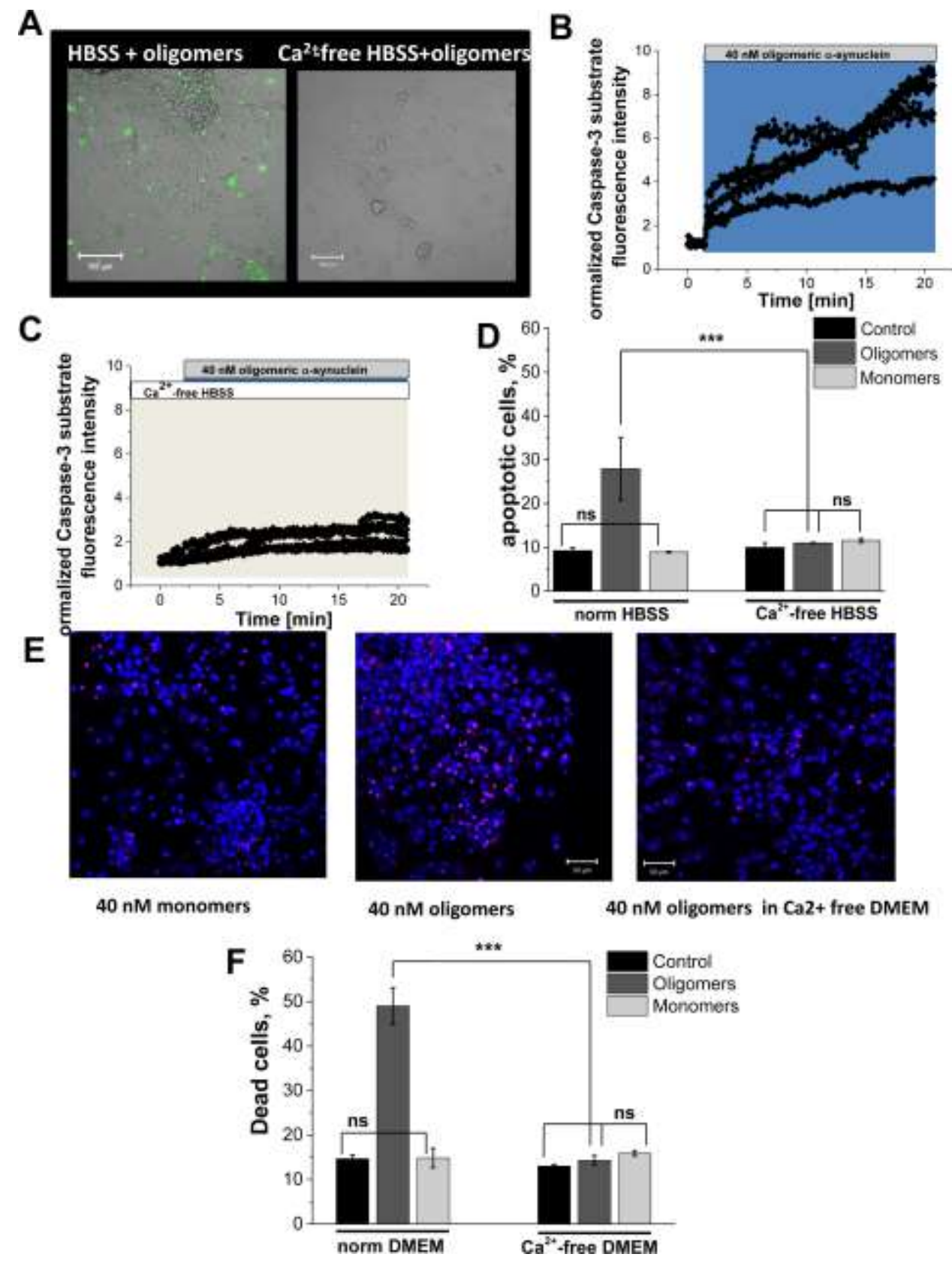

Figure 6: Protective effect of $\mathrm{Ca}^{2+}$-free medium against $\alpha$-synuclein induced caspase-3 activation and cell death. 
40nM oligomeric $\alpha$-synuclein significantly activates the NucView 488 caspase 3 substrate in neurons and astrocytes (A, B, D). Pre-incubation in $\mathrm{Ca}^{2+}$-free medium significantly reduced caspase 3 activation $(\mathbf{C})$, shown as the time from addition of the peptide to activation of the substrate, i.e. increase of fluorescence at the nucleus (A).(D) Quantification of $\alpha$-synucleininduced apoptosis in calcium containing and calcium free medium. (E) Cell death was assessed using PI to label dead cells and Hoechst to label all cells. (F) Quantification of $\alpha$ synuclein-induced cell death in normal and $\mathrm{Ca}^{2+}$-free medium. 